\title{
KHARTOUM AND HYBRID DISASTERS
}

\author{
MASHER IMAD AHMED MOHAMED \\ College of Architecture, University of Khartoum, Sudan
}

\begin{abstract}
The present study is an effort to prove that hybrid disaster (flood and flash flood) is the real result of human intervention in the natural phenomena in Khartoum. In recent years, floods and flash floods have threatened urban areas, causing effects on the physical environment and the social fabric of the state, which in turn has weakened the principles of urban sustainability in the study area. Understanding and knowledge of the types of disaster are key to determining actual causatives; therefore, the process of correctly classifying the disaster helps to achieve the optimum solutions in the problem under study. There are many reasons behind the disaster and the incapacity to handle it. The most important are: unstudied urban growth, the urban domination of Khartoum State, failure to control population increase, the lack of comprehensive schemes that integrate risk reduction as a basic element into the planning process. Lack of coordination between the competent authorities to reduce these disasters, migration and exodus because of civil wars, the community's lack of perception of the risk and living in the main tracks of the River Nile are also vital causes of disaster. The study recommends the integration of risk reduction into the planning process at all the various stages; creating a planning model to reduce the overall phases of disaster risk; parallel development in other areas of the Sudan to reduce the state's rate of exodus and migration; retrofitting the current urban plans by the expected climate indicators; and establishing controls and urban laws for building near the River Nile. The paper concludes by developing a model for risk-reduction integration with the planning process at all stages of the disaster in the study area.
\end{abstract}

Keywords: hybrid disaster, urban sustainability, urban domination, risk reduction.

\section{INTRODUCTION}

In spite of the economic crisis and civil wars, the government and community of Khartoum are working together to preserve the natural resources and reduce the potential risks; however, the River Nile represents the backbone of the study area; throughout the ages, people have always searched for water sources proportionate to the importance of water in life and, therefore, Khartoum city formed on the shores of the river. The Nile tried to resist this urban growth in order to maintain its natural course, but the high and unplanned increase in the population and society's unawareness of the sustainability of this resource led to floods and flash floods in the study area. The risk of hybrid disasters has become one of the biggest problems affecting the economies of developing countries in terms of the inability to face disasters, the material and moral losses for the affected areas and the demolition of one of the principles of sustainable development.

\section{WHAT IS A DISASTER?}

Disasters are considered results of natural phenomena; whenever there is a disaster, it definitely leads to risks, which in turn threaten aspects of life in the affected area.

In order to know the extent of the effect of a disaster and how to reduce hazards, it is first necessary to understand the causes and what leads to it being classified as a disaster. In order to properly define and categorize disasters, it is necessary to have prior knowledge of the source and to understand the way they happen. 
2.1 Natural phenomena, hazard, vulnerability, disaster

The difference between natural phenomena and natural disasters comes from the human presence in the area of the phenomena. Therefore, if an earthquake or flood occurs in a nonpopulated area, the event is a normal natural phenomenon; however, if humans encroach on those areas, they become vulnerable to disasters [1].

It is therefore important to know that the disaster is an interconnected ring - starting as a natural phenomenon that leads to hazards - which, with the presence of vulnerability, ends in a disaster.

Accordingly, a disaster could be defined as a set of events that consists of the form of the phenomenon, resulting from an episode portending danger, and ending in disaster in various ways not restricted to the laws of the natural environment because of human intervention in the natural phenomenon.

Disaster in Sudan occurs as a result of hydrological phenomena, and the main source is sunlight because it is tropical country; therefore, the disasters in most areas are flash flood, flood, drought, and desertification.

\section{HOW A DISASTER OCCURS}

A disaster mainly occurs when vulnerability and hazard meet. The interaction and association of such phenomena are depicted below in Fig. 1 [3].

\section{TYPES OF DISASTER}

All the books and research refer to two types of disaster: natural disaster and human-made disaster [3]. However, the author disagrees with this classification; there is another type of disaster, which is hybrid disaster. A hybrid disaster can be defined as a natural phenomenon, where human intervention causes disorder that leads to big risk events, resulting in a disaster that exceeds the capacity of society to respond to it. The most important types of these disasters are flood and flash flood.

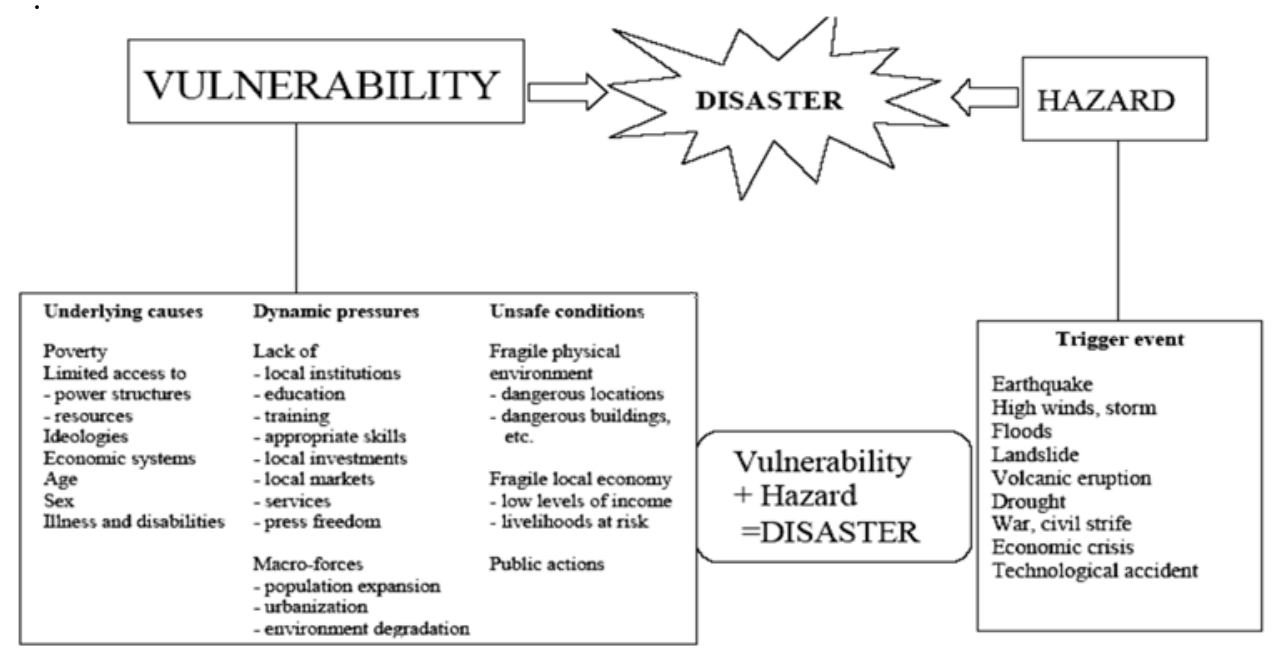

Figure 1: Relationships between vulnerability, hazard and disaster [3]. 


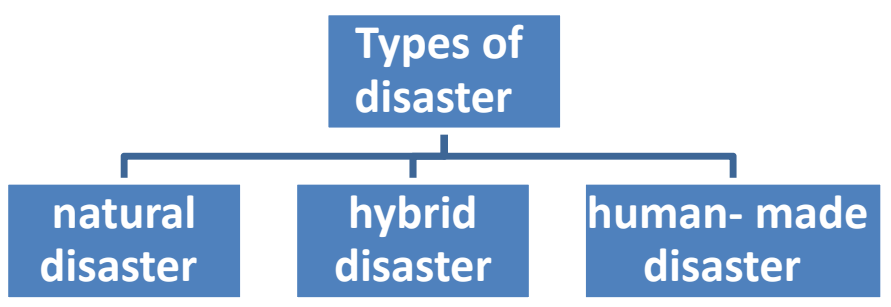

Figure 2: Types of disaster.

\subsection{The reasons for hybrid disaster}

Human behaviour is considered a main cause of hybrid disasters. However, there are many other reasons, as shown below:

- $\quad$ Failure to observe environmental elements at the national planning stage.

- Deficiencies in the strategic and regional planning levels.

- Lack of safe areas for displaced people from civil wars and other circumstances.

- Lack of adequate studies into the risks and disasters in populated areas.

- Ignoring the increase in population over the long and short terms at various planning stages.

\section{PHASES OF DISASTER}

The phases of a disaster are described in the following points below:

Prevention: Activities to provide outright avoidance of the adverse impact of hazards and the means to minimize related environmental, technological and biological disasters. Preparedness: Activities and measures taken in advance to ensure an effective response to the impact of hazards, including the issuance of timely and effective early warnings and the temporary evacuation of people and property from the threatened locations.

Mitigation: Structural and non-structural measures undertaken to limit the adverse impact of natural hazards, environmental degradation and technological hazards.

Response: The provision of assistance or intervention during or immediately after a disaster to meet the life-preservation and basic-subsistence needs of those people affected. It can be of an immediate, short-term, or protracted duration.

Recovery: Decisions and actions which are taken after a disaster with a view to restoring or improving the pre-disaster living conditions of the stricken community, while encouraging and facilitating necessary adjustments to reduce disaster risk.

Rehabilitation and reconstruction: Affords an opportunity to develop and apply disaster-risk reduction measures [4]. 


\section{THE RELATIONSHIP BETWEEN URBAN PLANNING AND DISASTERS}

Planning is an important tool in a nation's development. The relationship between urban planning and disasters arises from areas where there was no consideration for the signs of hazards during the planning process, besides the lack of integration of risk reduction into urban planning.

This is manifested in Khartoum, when floods and flash flooding occur as a result of high urban growth.

\section{DISASTER IN SUDAN}

Sudan has various resources. This variety stands on a careful balance of the components: climate, water, soil and human activity. As a result of climate change and the misguided use of water and soil, there is increased frequency in the occurrence of natural disasters [5].

Many disasters occur in Sudan, such as drought, floods and flash floods, desertification, conflicts, epidemics, and pests [5]. The reasons for disasters in Sudan include the repercussions of poverty, climate change, unplanned urbanization, poor land management, demographic change, the migration of population from rural to urban areas, weak institutional arrangements, aspects of the unsustainable use of natural resources, and the degradation of ecosystems [5].

\section{DISASTER IN KHARTOUM}

In recent years, development in Sudan has focused on Khartoum. As a result, the population left the villages and small towns, searching for better job opportunities. Consequently, those with low incomes find themselves living in dangerous locations in Khartoum; this causes environmental and economic problems for the urban environment and infrastructure.

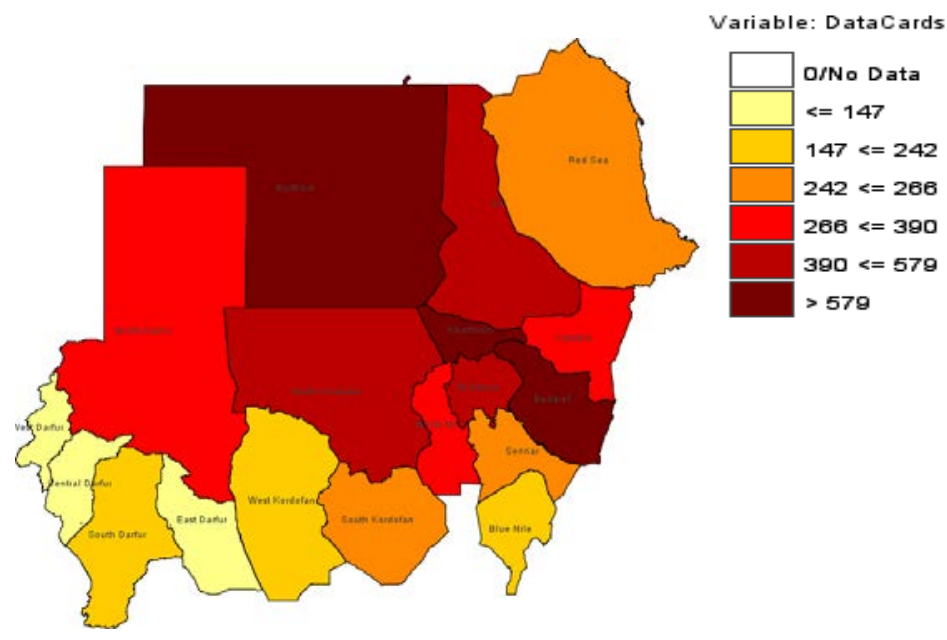

Figure 3: Disasters in Sudan 2005-2015 [6]. 


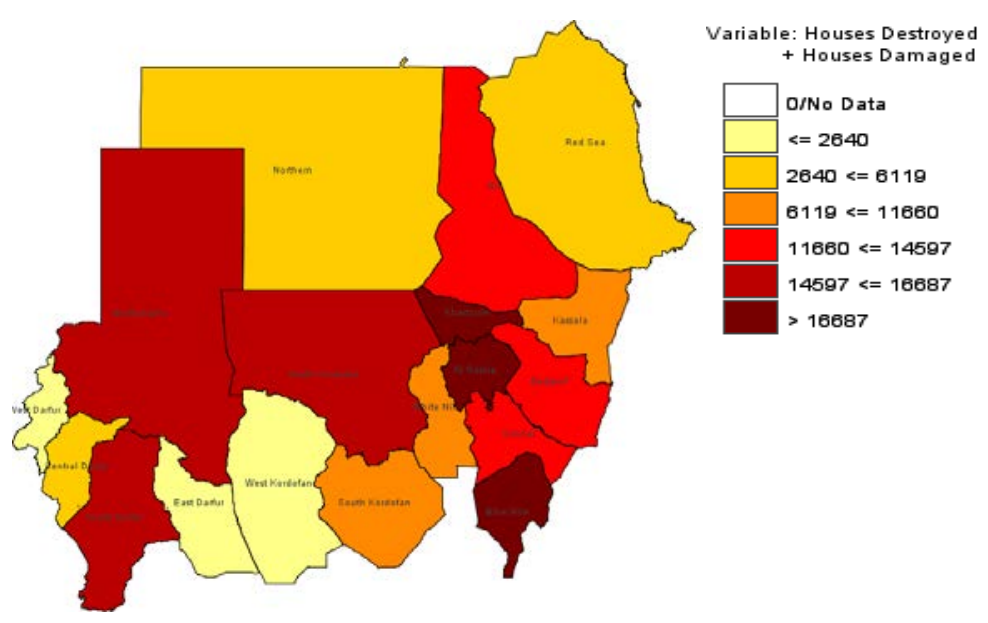

Figure 4: Disaster map (housing damaged and destroyed) in Sudan 2005-2015 [6].

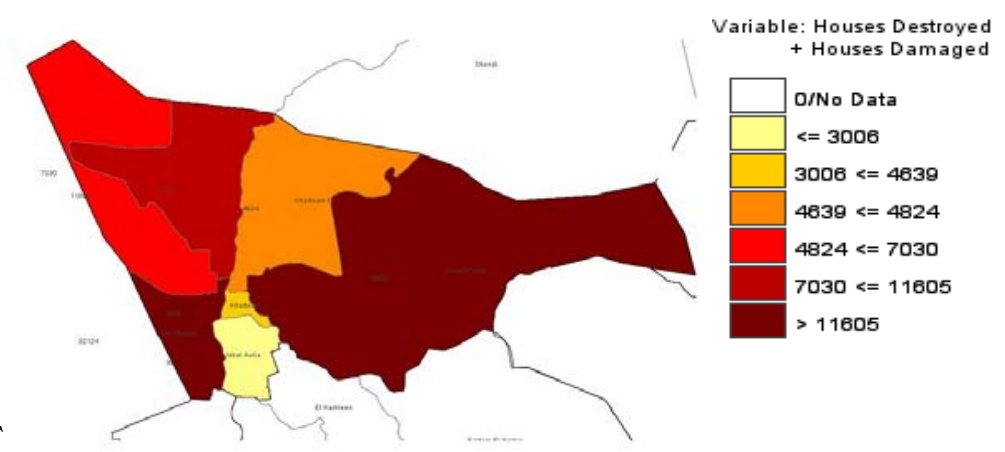

Figure 5: Flash flood in Khartoum 2005-2015 [6].

The concentration of population in Sudan, namely in Khartoum, has led to the vulnerability of land unfit for habitation and encroachment on the flood plain. Therefore, the hybrid disaster in Khartoum = vulnerability (physical fragility, dangerous locations, dangerous buildings, population expansion, urbanization) + hazard (floods, flash floods); see Fig. 6. 


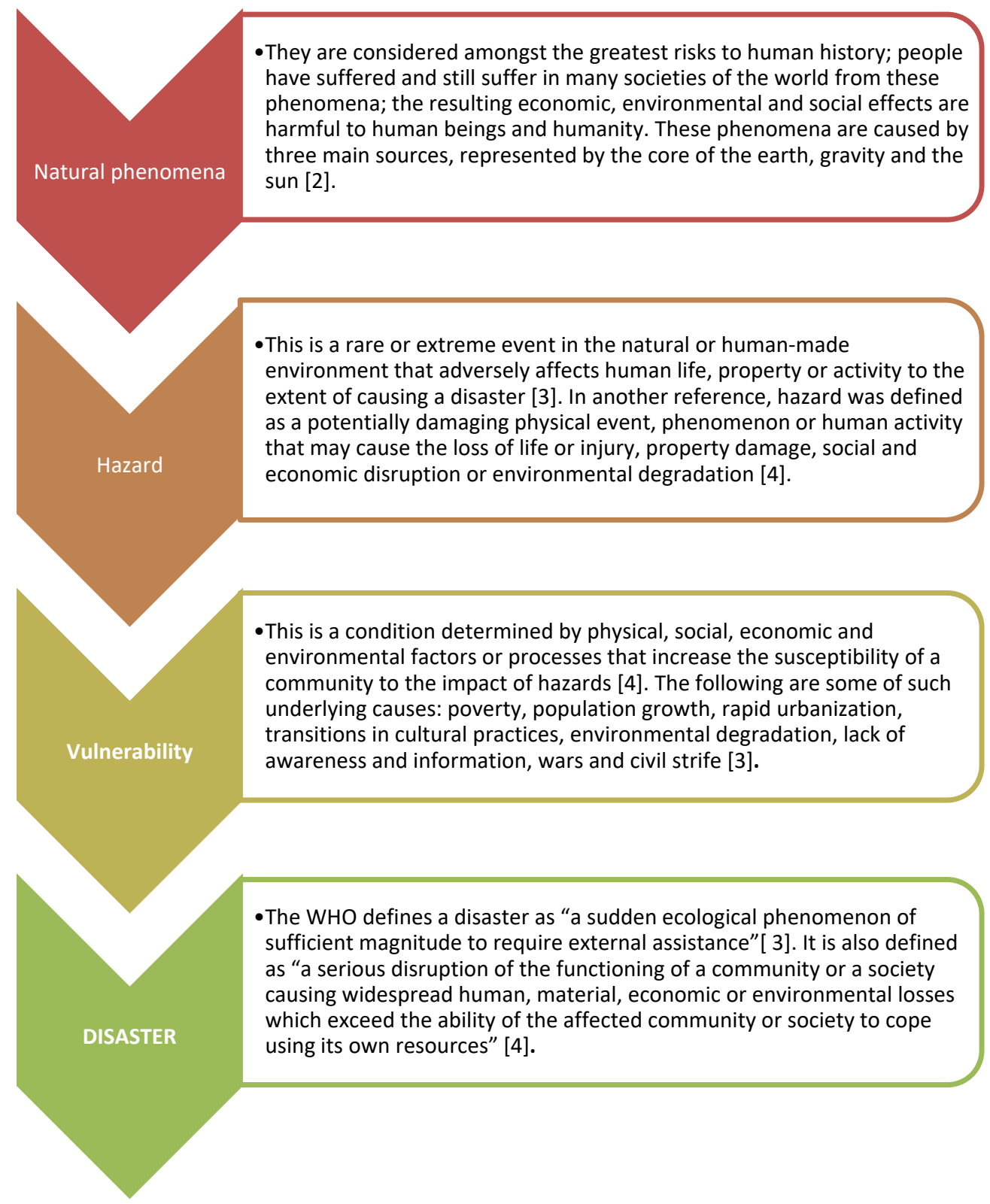

Figure 6: Natural phenomena, vulnerability, hazard and disaster.

The figure below shows that the rate of disasters in Khartoum; this supports the aim of the paper in the study area. This disaster Last years is a new type that can be treated with some discussion and measures in the planning. 


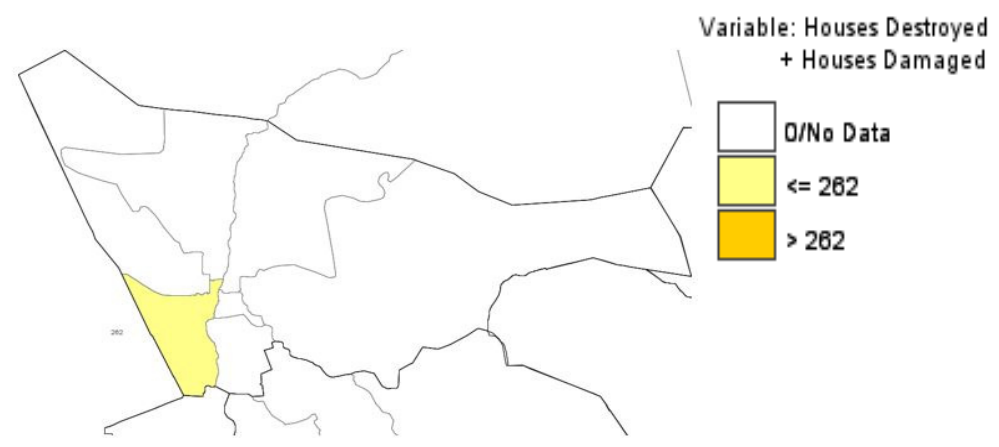

Figure 7: Flood in Khartoum 2005-2015 [6].

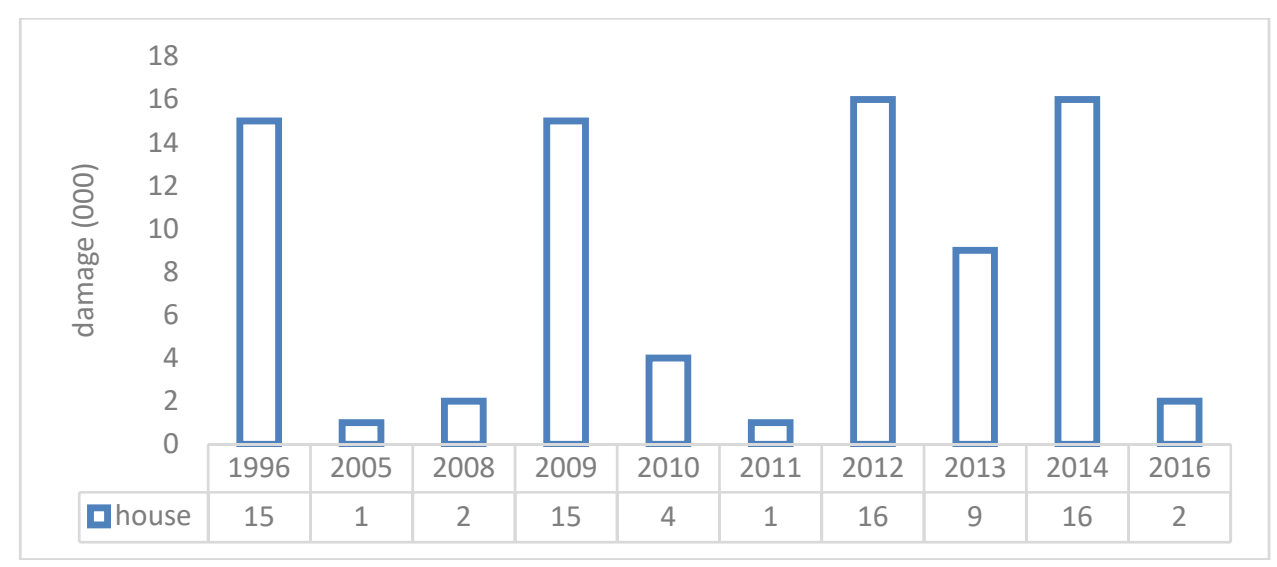

Figure 8: Diagram of flood and flash flood in Khartoum 2005-2013 [6].

The figure above shows the high rate of disasters in Khartoum; this supports the aim of the paper in the study area because the disasters that took place last year are unprecedented and need to be discussed in the planning stage.

\subsection{The reasons for hybrid disasters in Khartoum}

The unstudied urban growth in recent years led to the exodus of the people to Khartoum, searching for health and education services (Fig. 9), which in turn has inflated the population of the city of Khartoum.

The urban domination of Khartoum State: Khartoum is the biggest state in Sudan. It is mainly concentrated on the Nile strip with densely populated cities (Fig. 10). 


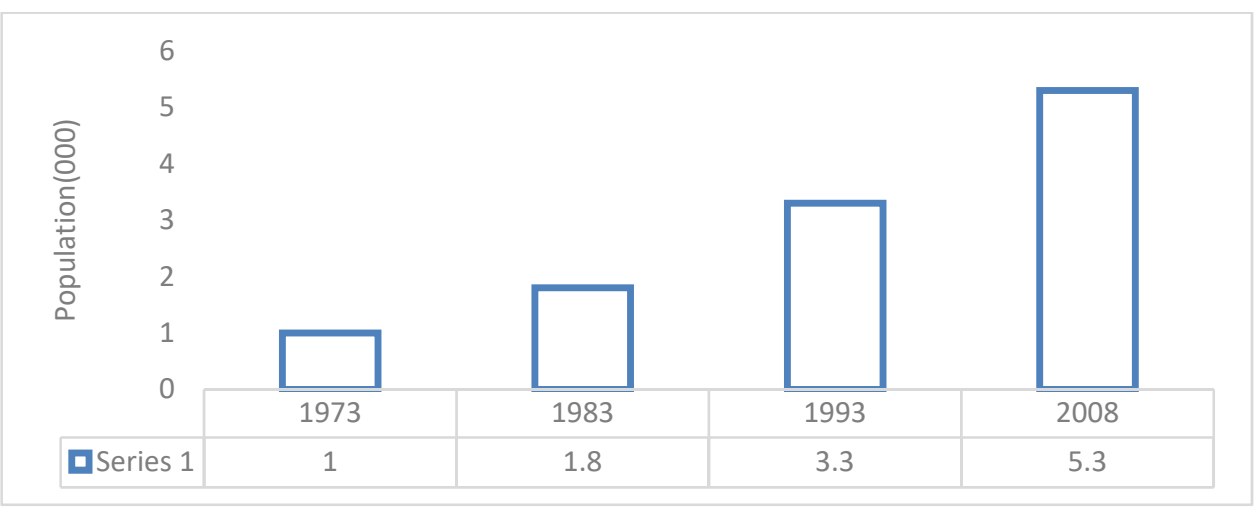

Figure 9: Total population rate in Khartoum [6].

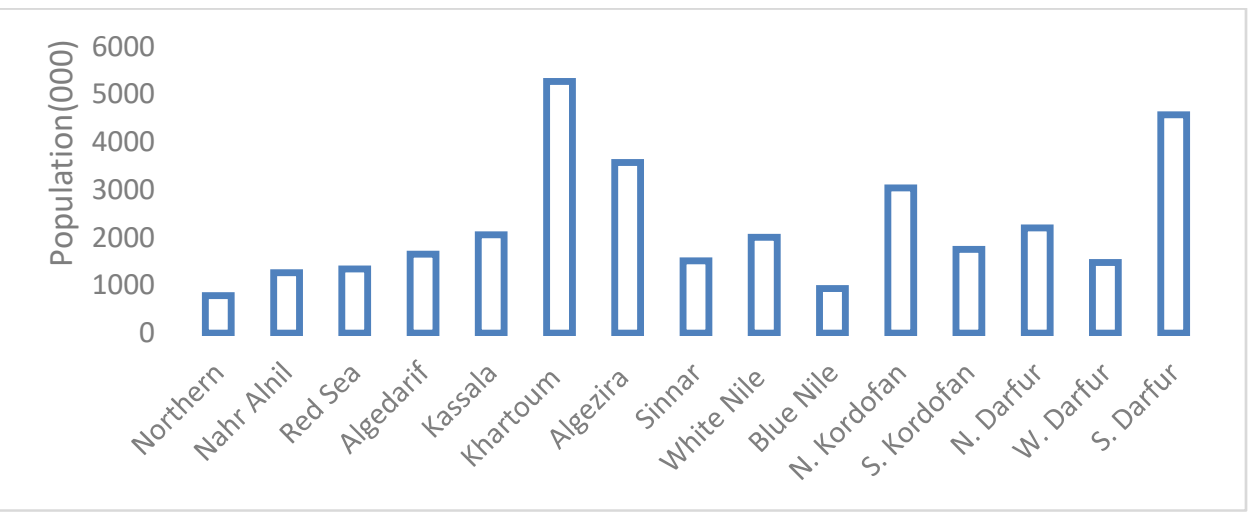

Figure 10: Urban domination of Khartoum 2008-2012 [7].

Failure to observe population increase: the success of development plans and urban planning depends significantly on the adoption of adequate studies of the population in terms of reducing risk in the real estate process; however, not all previous plans adequately anticipated population increase and the importance of parallel development in Sudan.

Climate change: this is the most important factor that should be taken into consideration in the planning process and for disaster-risk reduction; however, ignoring this important element leads to the occurrence of flood and flash flood in Khartoum; see Fig. 8 and Fig. 9. 


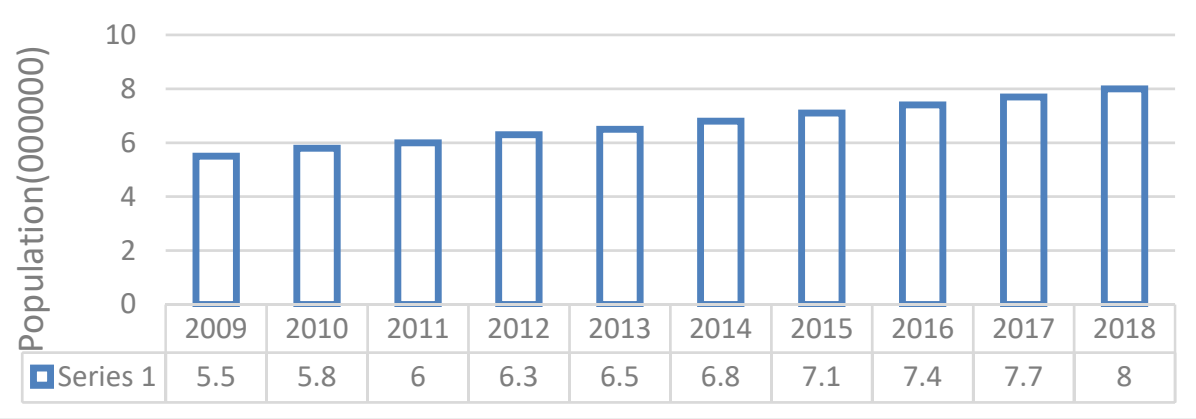

Figure 11: Estimation of population [7].

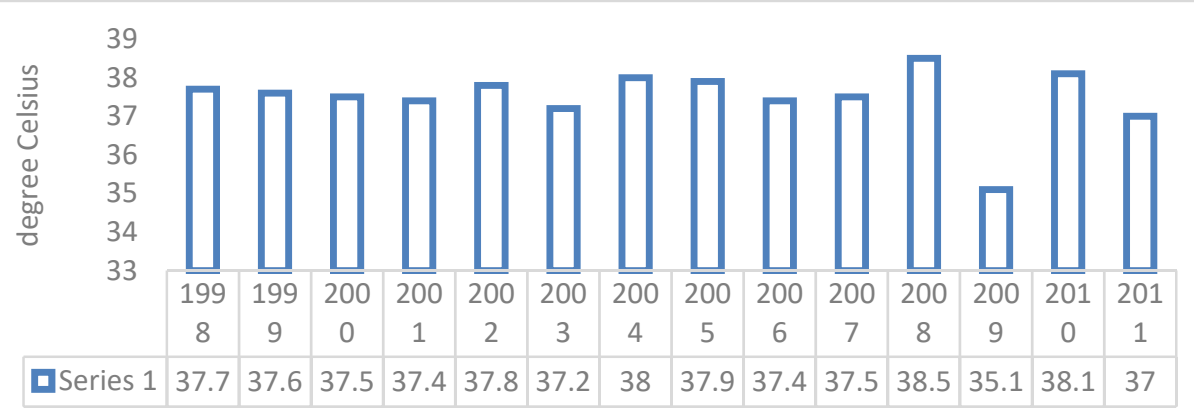

Figure 12: Average temperatures [8].

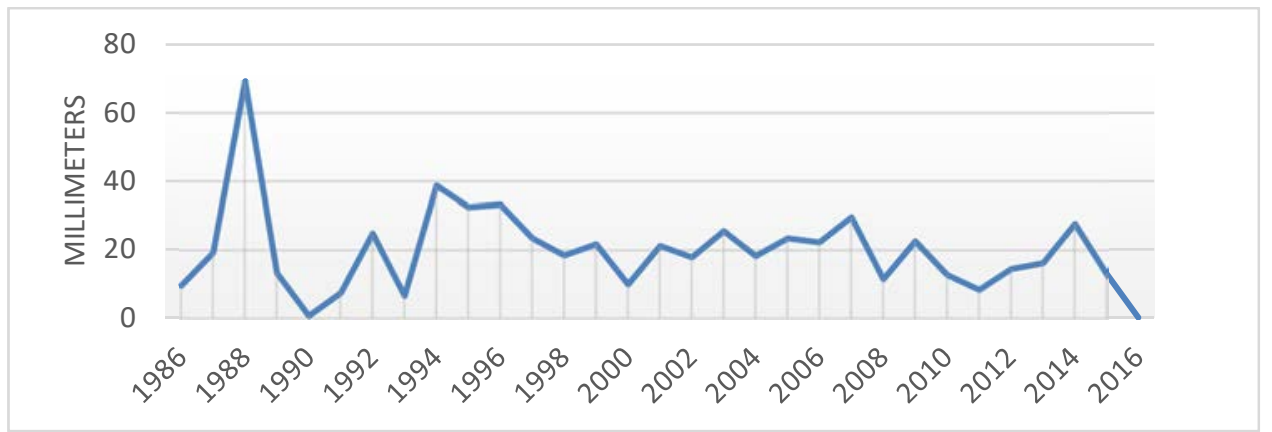

Figure 13: Rainfall rate from 1986 to 2016 [8]. 


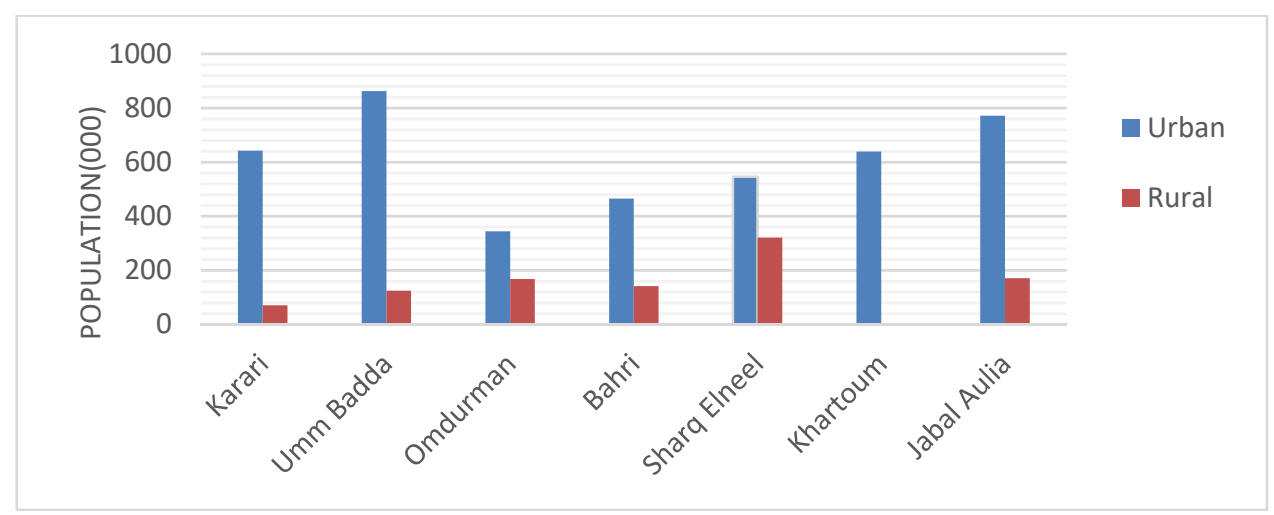

Figure 14: Distribution of population by lifestyle, urban and rural areas. [7].

There is a lack of comprehensive schemes, which integrate the reduction of disaster risk as a basic element in the planning process. This is obvious in Fig. 5, which shows the absence of disaster-risk reduction in the modern planning of Khartoum.

The population, which is unaware of the risk, live in the main tracks of the River Nile; this is illustrated in the link between Fig. 7, Fig. 5 and Fig. 14, which confirms that the rural areas in Khartoum were more exposed to flood and flash flood than other urban areas, especially the areas of Sharg Elneel and Omdurman.

The study recommends the following:

\section{RECOMMENDATIONS}

- Strengthening linkages through the development of a national strategy that incorporates all aspects in short and long-term plans.

- Integrating disaster-risk reduction into all the various stages of the planning process.

- Creating a planning model for all the phases of a disaster.

- Parallel development in other areas of the Sudan.

- Reducing the rate of exodus and migration to the capital, Khartoum.

- Retrofitting the current urban plans by the expected climate indicators.

- Establishing controls and urban laws for organizing the issue of living near the River Nile.

- Mainstreaming disaster-risk reduction into development planning as an essential factor of the sustainability of communities.

\section{CONCLUSIONS}

The paper concluded that hybrid disasters in the study area can be reduced through the integration of the proposed model shown in Fig. 14, with planning as an essential element. 


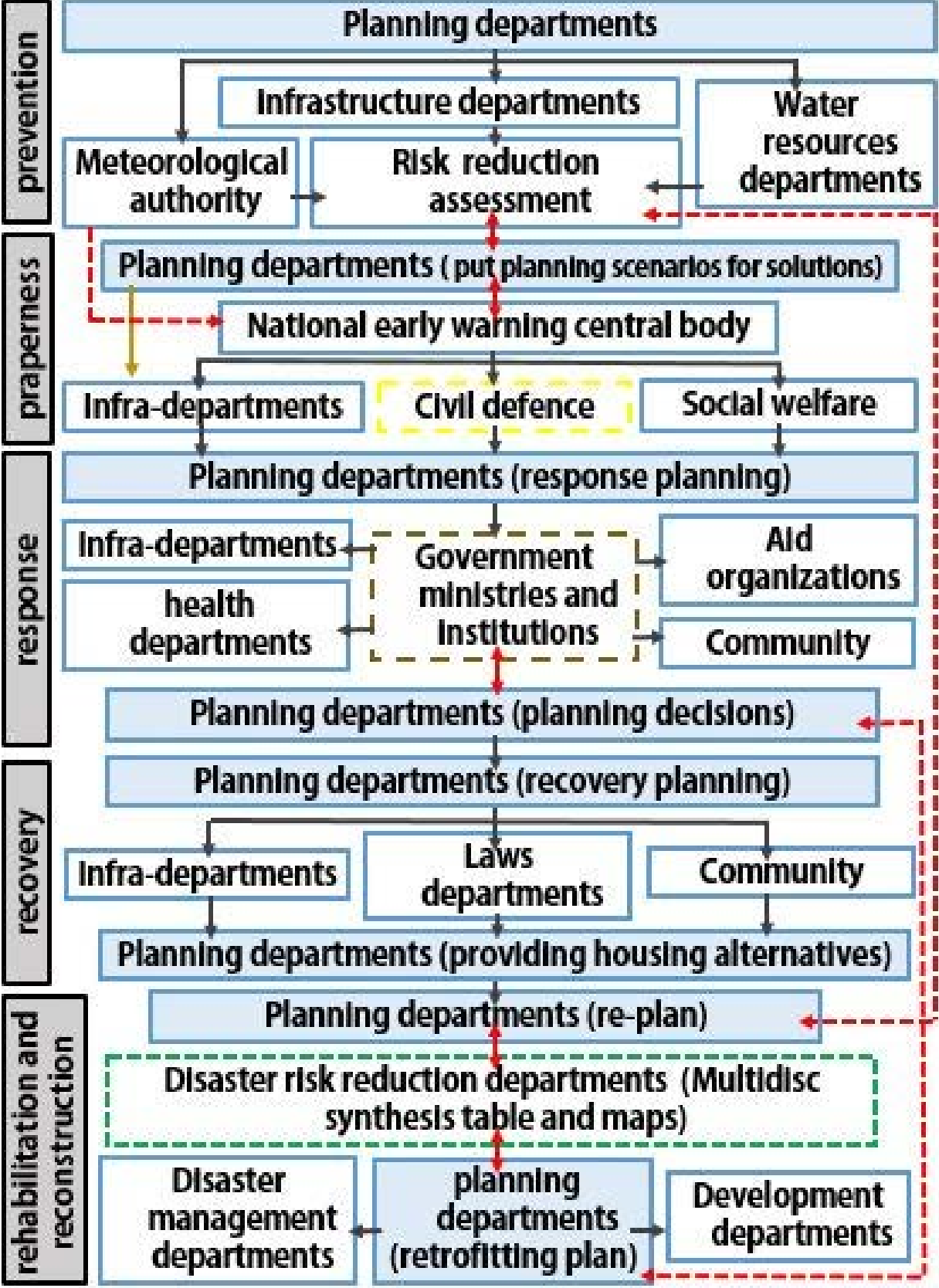

Figure 15: Model of hybrid disaster. 


\section{REFERENCES}

[1] The Impact of Natural Disasters on Re-planning Disaster Areas, Ain-Shams University, http://library.shams.edu.eg/eulc v5/Libraries/Thesis/Browse ThesisPages.aspx? $\mathrm{fn}=$ ThesisPicBody\&BibID=9961160\&TotalNoOfRecord=380\&Pag eNo=1\&PageDirection=First. Accessed on: 15 Jan. 2017.

[2] United Nations Educational, Scientific and Cultural Organization (UNESCO), Natural Phenomena (Towards Building a Culture of Prevention of Catastrophes in the Arab Countries), p. 9, Cairo, 2009.

[3] Sena, L. \& Woldemichael, K., Disaster Prevention and Preparedness, Lecture Notes - For Health Science Students. Jimma University, 2006.

[4] USAID, Planning for Disaster Risk Reduction (book3), Urban Governance and Community Resilience Guides, 2010.

[5] Humanitarian Aid Commission, Sudan, 23 Nov. 2016.

[6] National Council for Civil Defence, Sudan. National Disaster Risk Management Programme in Sudan, 2016, www.sudld-nccd.gov.sd. Accessed on: 24 Nov. 2016.

[7] Central Bureau of Statistics, Sudan, Dec. 2013.

[8] Sudan Meteorological Authority, Sudan, Nov. 2016. 